\title{
Seyahat İşletmelerinde Bilgi Teknolojilerinin Rolü ve Küresel Dağıtım Sistemlerine Bir Örnek: AMADEUS
}

Gökçe YÜKSEK, Yrd. Doç. Dr.,Anadolu Üniversitesi, Turizm Fakültesi. e-mail: gozer@anadolu.edu.tr

ÖZET

Bilgi teknolojileri ve küreselleşmenin beraberinde getirdiği değişimlerden seyahat işletmeleri de etkilenmektedir. Bilgi teknolojileri, işletmelerin rekabet üstünlü̆g̈̈ elde etmelerine yardımcı olmaktadır. 1980'li yıllarda gelişen küresel dağıtım sistemleri seyahat işletmeleri üzerinde önemi bir yere sahiptir. Bu sistemlere dâhil olmayan işletmeler ise ciddi sorunlar ile karşı karşıya kalmaktadır. Bu araştırmanın amacı seyahat işletmelerinde bilgi teknolojilerinin önemini önde gelen küresel dağıtım sistemlerinden biri olan AMADEUS örneği ile değerlendirmektir. Betimsel analiz yapılan araşstımada literatür taranarak seyahat işletmelerinde bilgi teknolojilerinin rolü açıklanmıştır. Örnek küresel dağıtım sistemi AMADEUS incelenerek de küresel dă̆̆tım sisteminin işleyişi incelenmiştir.

Anahtar Kelimeler: Bilgi teknolojileri, Seyahat İşletmeleri, Küresel Dağıtım Sistemleri, AMADEUS

\section{Role Of Information Technologies In Travel Business And Case Of Global Distribution System: AMADEUS}

ABSTRACT Travel businesses are also being affected by alterations which information technologies and
globalization bring along. Information technologies help businesses to gain a competitive edge.
Global distribution systems improved during 1980s have an important position on travel
businesses. Businesses do not participate in these systems encounter with serious problems.
The aim of this study was to evaluate the importance of information technologies in travel
businesses with the example of AMADEUS, one of the leading global distribution systems. In
the research descriptive analyzes used, the role of information technologies in travel businesses
was explained by literature search. Study investigated the process of global distribution system
by the example of global distribution system AMADEUS. 


\section{Giriş}

Dünya; sermayenin uluslararası akışkanlığının artışı, ortaklıkların öneminin artması, sahiplik yapılarının değişmesi, stratejik işbirliklerinin önem kazanması ve ekonomik yapılardaki değişimle yeni bir sürece girmiştir. $\mathrm{Bu}$ süreç küreselleşme sürecidir.Küreselleşmenin temelini bilgi teknolojileri oluşturmaktadır. Bilgi teknolojileri işletmelere yeniliklerin izlenmesi, yönetim ve üretim süreçlerinde yenilikleri kullanma konusunda destek olmakta, karar alma süreçlerine ve kontrol süreçlerini düzenlemelerine katkıda bulunmaktadır. En dar anlamıla bir bilgi sisteminin teknolojik yanını ifade eden bilgi teknolojileri, bilgisayar ve iletişim teknolojilerinin gelişiminin bir sonucudur.

Yeni bilgi teknolojileri özellikle seyahat işletmelerinin verimliliğini yakından ilgilendirdiği gibi, işletmelerin rekabet güçlerinin artmasına, pazarlama faaliyetlerinin etkin olmasına yardımcı olmaktadır. Günümüzde gelişen bilgi teknolojilerine ayak uyduramayan işletmeleri faaliyetlerini sonlandırmaya gidecek kadar ciddi sorunlar beklemektedir.

\section{Literatür}

\section{Bilgi Toplumu, Bilgi Teknolojileri ve Turizm}

Dünyada değişim hızlanmıştır. Değişim sonucu bilgi toplumu denilen bir toplum ortaya çıkmıştır. Bilgi toplumunda, en güncel bilgiye, en güncel teknolojiye ulaşan, başarıya daha kolay ulaşabilmektedir. Ancak değişim ve bilgide sınır bulunmamaktadır. Her gün yukarıya doğru tırmanma devam etmektedir. Bunun için değişimi ve bilgi birikimini devamlı izlemek gereklidir. Çağdaş iletişim tekniklerini bilmek ve kullanmak mecburiyetinin doğduğu günümüzde, artık pek çok şeyin de şeffaflaştığı görülmektedir. Bilgiye ulaşmayı bilen, oturduğu yerden zaman ve para harcamadan istediği bilgiyi elde edebilmektedir (Sabancı, 1998). Bilgi toplumu, 1950 ve 1960'lı y1llarda A.B.D., Japonya, Batı Avrupa ülkeleri gibi gelişmiş ülkelerde bilgi teknolojilerinin giderek artan bir şekilde kullanımıyla ortaya çıkmış bir aşamadır. Gelişmiş ülkelerde şekillenen bu aşamanın en önemli özelliği, bilginin ve bilgi teknolojilerinin tarım, sanayi, hizmetler sektörlerinin yanı sıra eğitim, sağlık, iletişim gibi her alanda kullanılabilir olmasıdır. Bu nedenle, bilgi toplumundaki gelişmeler kısa sürede üretimin ve verimliliği artırmasına yol açmakta ve yeni teknolojik, ekonomik, sosyal ve kültürel gelişmeleri de teşvik etmektedir. Bilgi toplumundaki tüm bu gelişmeler diğer dünya ülkelerini de kısa zamanda etkisi altına almış ve uluslararası alanda ekonomik, siyasal, sosyal ve kültürel alanda entegrasyonu beraberinde getirmiştir (Aktan ve Tunç, 1998: 120).

İçinde yaşadığımız yüzyılda teknoloji, uluslararası ekonomik ve siyasal ilişkileri ve toplumların zenginlik düzeylerini belirlemede en önemli unsurlardan biridir. 19. yüzyılın sonlarında teknolojik gelişmelerle birlikte tarım toplumundan sanayi toplumuna geçilirken, 20. yüzyılın ikinci yarısında hızla gelişen ileri teknolojilerle birlikte sanayi toplumunun yerini bilgi toplumu almıştır. 
İşletmelerin küresel pazarda rekabet edebilmeleri büyük ölçüde yeni gelişmelere uyum sağlayabilmelerine bağlı görünmektedir. İşletmelerin büyük miktarlarda bilgiyi ele geçirebilmeleri, saklayabilmeleri ve işleyebilmeleri onlara rekabetçi bir avantaj sağlamaktadır. Bilgiye hızla ulaşan, işleyen, yönetsel çıktıya ve eyleme dönüştürebilen işletmeler varlığını sürdürebilmenin yanında rekabet ortamında diğer işletmelerin önüne geçme koşullarını da sağlamış olacaktır. Koşulların hızla değiştiği, bilginin değerinin her geçen gün arttığı bir çevrede işletme için gerekli bilgilerin toplanması, saklanması, işlenmesi süreçleri bilgi teknolojileri kullanımını zorunlu kılmaktadır. Teknoloji bu anlamda, işletme yönetim, üretim, kalite süreçlerinin verimli ve etkin kılınmasına olanak sağlamaktadır (Yolal, 2003: 8).

Bilgi teknolojilerinin başlangıcı, bilgi, bilgisayar ve iletişim arasındaki ilişkiye dayanmaktadır. Düşünen ve işlem yapabilen makineler yapma düşüncesi çok eskilerden beri varolmuştur. Mekanik bilgi işleme araçları olarak, BlaisePascal'ın (1640) aritmetiksel işlemler yapan makinesinden, Joseph Marie Jacquard'ın (1804) özdevimli mekanik hesaplayıcısında, HermanHollerith'in (1880) delikli kartlarına dek uzanan gelişim evriminin elektronik ilk halkasını 1946 yılında ortayaçıkan ENIAC (Electronic NumericalIntegratorandCalculator) oluşturmuştur (Erdoğan ve Erdoğan; 1996: 18).

Buhalis (1998), bilgi teknolojilerini bilginin elde edilmesi, analizi, depolanması, yayılması ve uygulanmasında yararlanılan bilgisayar, elektronik ve iletişim teknolojilerindeki son gelişmeleri tümünü ifade eden bir kavram olarak tanımlamaktadır. Makroekonomik düzeyde bilgi teknolojileri bir bölgenin küresel pazarda rekabet gücünün yanında refah ve gelişmişlik seviyesini belirleyen bir araç haline gelmiştir. Mikro ekonomik düzeyde ise, bilgi teknolojileri stratejik yönetimin ve işletme yönetiminin bütün fonksiyonlarını etkilerken işletmelerin rekabet gücünü de belirlemektedir.

Bilgi teknolojileri günümüzde turizm işletmeleri için, turistik ürünlerin tanımlanması, tanıtımı, dağıtılması ve bir araya getirilmesi, organize edilerek tüketiciye sunulmasında sürdürülebilir rekabet avantajı elde etmede stratejik bir silah haline gelmiştir (Buhalis ve Main; 1998).

Turizm işletmelerinin, potansiyel tüketiciler için büyük miktarlarda bilgi toplama ve yayma ihtiyacı, bu işletmeleri bilişim teknolojisini kullanmada en önemli aday haline getirmektedir. Bu işletmelerin heterojen doğası, bilgi-iletişim teknolojileri kullanımının sektörden sektöre ve sektör içindeki işletmeden işletmeye değişim göstermesi anlamına gelmektedir (Mutch, 1995).

Bilgi teknolojilerinin gelişmesi, özellikle verimli işbirliği sağlaması ve gerçek bir küreselleşme için araçlar sunması dolayısıyla, turizm endüstrisi yöneticileri için yeni uygulama alanları doğurmuştur. Günlük faaliyetlerin temel olduğu işletmelerde bilginin yaratılması, toplanması, işlenmesi ve iletilmesinin hayati önem taşımasından dolayı; bilgi teknolojileri beklenmedik bir şekilde turizm işletmelerinin en önemli elemanlarından biri haline gelmiştir. Yani; hem turizm arzının hem de turizm talebinin hızlı gelişimi, bilgi teknolojilerini endüstrinin zorunlu bir ortağı haline getirmiştir ve bu nedenle bilgi 
teknolojileri, turizm pazarlaması, dağıtımı, promosyonu ve koordinasyonunda artan bir şekilde önemli bir rol oynamaktadır (Coşkun ve Yüksek, 2010).

Turizm sektörü de teknolojik devrime bağlı gelişen değişimlerden etkilenmiştir. Bilginin, turizm sektörü çok önemli olması, bilgi teknolojilerinin sektörde kullanılması büyük avantajlar sağlamaktadır. Turistik ürün ve hizmetlerin, satın alınmadan önce satış noktasında incelenme olanağ 1 yoktur. Tüketilmeden önce ve tüketileceği yerden farklı bir yerde satın alınırlar. Bu yüzden turistik hizmetlerin tüketiciyi çekebilmesi,turizm işletmelerin sunduklarını hizmeti tanıtmalarına bağlıdır. Tüketici beklentilerine uygun, doğru ve güncel bilgi turistlerin tatmini için çok önemlidir. Bilgi teknolojileri turizm sektörünün gereksinim duyduğu bilgi altyapısını sunmaktadır.

Yeni teknolojiler turizm işletmelerinin faaliyetlerini yürütme şekillerini, iletişim yöntemlerini, tüketicilerin bilgi arama ve turistik hizmet ve ürün satın alma yollarını değiştirmektedir. Turizm işletmeleri bilgisayarlı rezervasyon sistemleri -CRS- ve elektronik satış noktaları gibi rezervasyon ve bilgi yönetim sistemleri kullanmaya, küresel dağıtım sistemlerinin içinde yer almayabaşlamışlardır. İnternet, turizm işletmelerinin faaliyetlerinde belki de önemli bir araç haline gelmiştir. Yeni teknolojiler turizm işletmelerini rekabet güçlerini artırabilmek için yeniden yapılanma süreçlerini uygulamak gibi kimi arayışlara itmektedir.

\section{Araştırmanın Amacı ve Yöntemi}

$\mathrm{Bu}$ araştırmanın amacı seyahat işletmelerinde bilgi teknolojilerinin önemini önde gelen küresel dağıtım sistemlerinden biri olan AMADEUS örneği ile değerlendirmektir. Betimsel analiz yapılan araştırmada literatür taranarak seyahat işletmelerinde bilgi teknolojilerinin rolü açıklanmıştır. Örnek küresel dağıtım sistemi AMADEUS incelenerek de küresel dağıtım sisteminin işleyişi incelenmiştir.

\section{Seyahat İșletmelerinde Bilgi Teknolojilerinin Rolü}

Seyahat işletmeleri perakendeci satış acentaları ile toptancı seyahat acentaları ve tur operatörlerini ifade eder. Bu işletmeler tüketicilere turistik ürün ve hizmetleri bir arada ya da ayrı ayrı sunan kuruluşlardır. Günümüzde seyahat işletmelerinin çoğu bilgi teknolojilerinin olanaklarından faydalanmaktadır. Zira sürdürülebilir rekabetin olmazsa olmazı olan teknoloji seyahat işletmelerinin de vazgeçilmez unsuru olmuştur.

Bilgi teknolojilerinin seyahat işletmeleri üzerindeki etkisi pek çok yazar tarafından tartışılmaktadır (Buhalis, 1998; Cooper vd. 1998; Adams, 2002; Kurgun vd. 2007; Yılmaz \& Yilmaz, 2004).

Birkan 1998; Pemberton vd. 2001 ve Zhou 2004'te belirttikleri üzere; bilgisayarların, 1950'lerdeki seyahat sektörüne, elverişli ve hizlı bir sistem olan "Merkezi Rezervasyon Sistemleri" ile hızlı girişi, günümüzde var olan bilgisayar teknolojisi ile seyahat acentalarındaki işlemlerin, en iyi şekilde, en kısa zamanda en az maliyetle ve kesin rezervasyonlu olarak gerçekleşmesine olanak tanıyan "Küresel Dağıtım Sistemleri" ile devam etmiştir (Hançer ve Ataman, 2006). 1970’lerde Merkezi Rezervasyon Sistemleri, 
1980'lerde ise Küresel Dağıtım Sistemleri gelişmiş olup bunları 1990'lı yıllarda internet izlemiştir. Merkezi rezervasyon sistemleri ve küresel dağıtım sistemleri; seyahat, konaklama, eğlence hizmetleri, turistik çekim bölgeleri ve tatil paketleri gibi bilgileri içerir. Bu hizmetler aynı zamanda büyük derecede esnekliğe izin vermektedir. Müşterilerin son anda rezervasyonlarını gerçekleştirerek ve bu rezervasyonların da hızlı bir şekilde onaylanmasını gerçekleştirebilmektedirler. Bilgi sistemleri aynı zamanda pazar araştırmaları ile müşteri isteklerinin anlaşılması için yardımcı olmaktadır (Buhalis, 1998). Ayrıca, bilgi sistemleri seyahat işletmelerinin verimliliği ve kârlılı̆̆ üzerinde önemli bir role sahiptir.

IBM ve AmericanAirlines ortaklığ 1 ile geliştirilen, daha sonra Yarı Otomatik İş Araştırma Ortamı adiyla (Semi- Automated Business Research Environment/ SABRE) faaliyetlerine devam eden ilk merkezi rezervasyon sisteminin rezervasyon programlarl; havayolu şirketlerinde, havayolu personelinin, koltuk müsaitliğinin daha etkin yönetilebilmesini sağlamıştır (Zhou, 2003:157).

Buhalis (1998), havayolu şirketleri tarafından kullanılmaya başlayan bilgisayarlı rezervasyon sistemleri yeni seyahat pazarlaması ve dağıtım sistemini oluştururken elektronik çağın da başlangıcı olarak görüldügüüü ifade etmektedir. Bilgisayarlı rezervasyon sistemleri, satış büroları ve satış ortaklarına elektronik dağıtımı gerçekleştiren ve turizm işletmelerinin stoklarını yürüten bir veri bankasıdır. Bilgisayarlı rezervasyon sistemleri turizm işletmesi yöneticilerinin getiri yönetimi uygulamalarını kolaylaştırırken turistik ürünlerin küresel ölçekte kontrolü, tanıtımı ve satışını sağlamaktadır. Diğer dağıtım kanallarına göre bilgisayarlı rezervasyon sistemleri rekabete uygun komisyon oranları belirlenmesini sağladığından, arz ve talep dalgalanmalarını karşılayacak esnek fiyatlandırma ve kapasite düzenlemelerine olanak vermektedir (Kurgun vd., 2007' de belirttiği üzere).

Günümüzde artık elektronik iletişim ağının her geçen gün güncelliğinin artması seyahat işletmeleri ile ilgili pek çok konuda turistlere kolaylık sağlamaktadır. Bu kolaylıklardan bazıları (Yarcan, 1998: 64);

- $\quad$ Rezervasyonların gerçekleştirilmesi,

- Uçak biletlerinin otomatik bilet satış makinelerinden alınması,

- $\quad$ Seyahat ile ilgili her türlü bilginin sağlanması (turistik ürün hakkında, döviz kurları vb.) olarak sayılabilir.

\section{Küresel Dağıtım Sistemlerinin (Global Distribution System-GDS)Gelișimi}

Seyahat İşletmelerinde bilgi teknolojilerinin gelişimi konusunda bilgisayarlı rezervasyon sisteminden sonra küresel dağıtım sistemleri gelmektedir. Küresel dağıtım sistemleri, farklı rezervasyon sistemlerinin birleşmesiyle (havayolu işletmeleri, tur operatörleri, oteller, araba kiralama şirketleri vb.) ortaya çıkan sistemlerdir (Yarcan, 1998, 117). Küresel dağıtım sistemi kavramı, ürün dağıtımı ve dünyanın farklı ülkelerindeki sistemlere dâhil olmak için bir veya daha fazla merkezi rezervasyon sistemini ifade etmektedir. Dağıtım, turizm işletmelerinin rekabet gücünü ve performansını artırmasını sağlayan pazarlama karmasının önemli elemanlarından biridir. Doğru pazarlama karmasının doğru pazar dilimlerine doğru aracılar 
ile dağıtımı uzun dönemli başarı açısından önemlidir. 21. yüzyılda bilinen en etkin dağıtım sistemi düşük maliyet olanağı sağlayan küresel dağıtım sistemleridir. Küresel bilgi veri tabanı uygulamaları sadece seyahat pazarında değil, birçok alanda gelişmiştir. Küresel Veri Uyumlaştırma (Global Data Synchronization - GDS) tedarik zinciri üzerinde etkinlik artısı yanında birçok başka faydalarda yaratmıştır. Küresel veri uyumlaştırma sistemi paketlenmiş gıda ve perakende sektöründe tasıma maliyetlerinde tasarruf ve yüksek gelir arısı etkisi sağlamıştır (Kurgun vd., 2007: 265). Küresel dağıtım sistemleri, işletmelerin maliyetlerini azaltırken verimliliklerini arttırmaktadır.

Küresel dağıtım sistemleri çok sayıda işletme ile bağlantılıdır ki bu gerçekten karmaşık bir yapıdır (Şekil 1.) Bu karmaşık görünen yapıya rağmen küresel dağıtım sistemleri sistematiğin sağlanmasında, bilgi aktarımında, iletişim sağlanmasında arz ve talep sağlayıcılarını karşılaştıran çok önemli sistemlerdir.

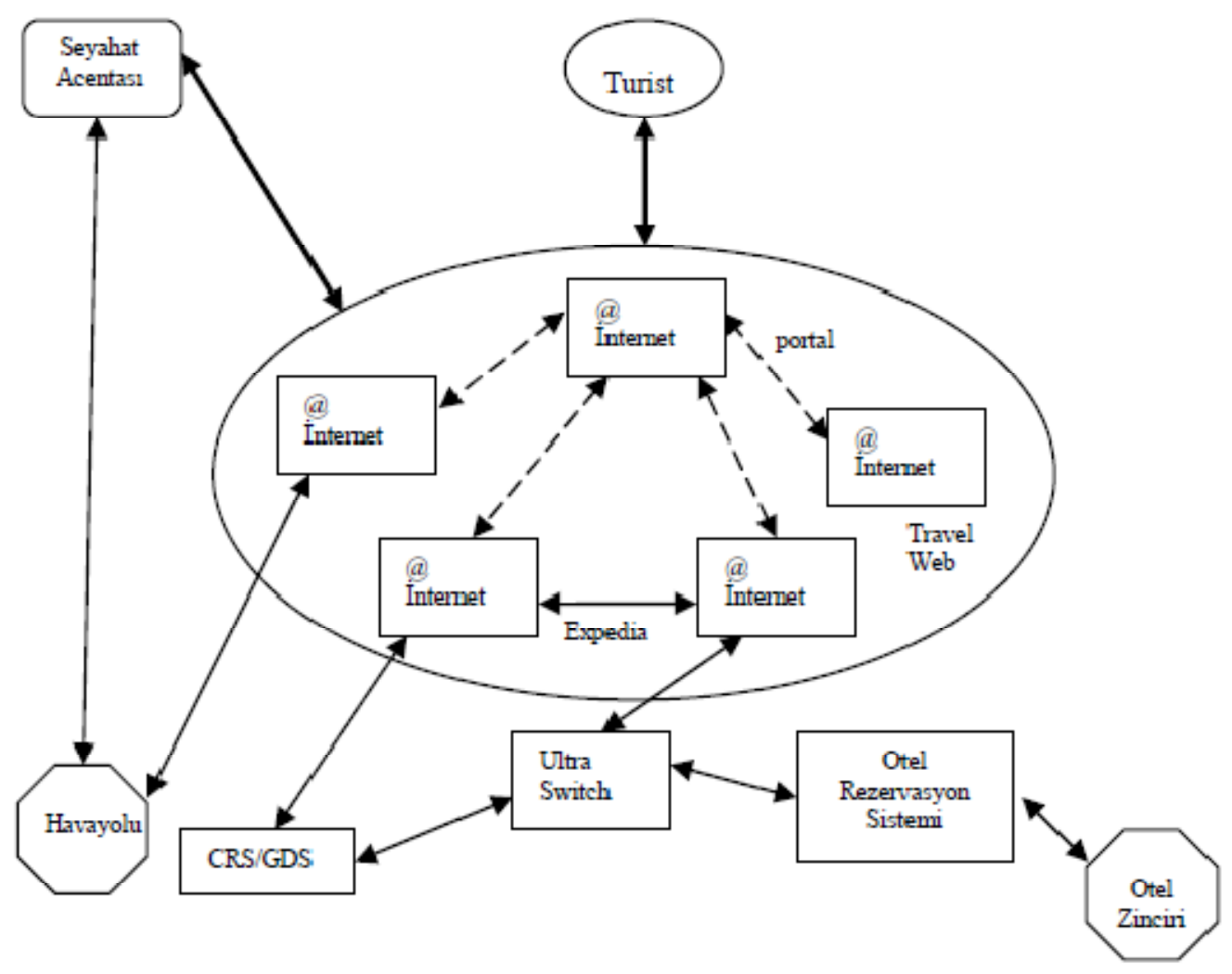

Şekil 1. Küresel Dağıtım Sisteminde İşleyiş

Kaynak: Kurgun vd. 2007, 268.

Küresel dağıtım sistemlerinin seyahat işletmelerine sağladığı faydaları;

- Biletleme,

- Rezervasyon, 
- Satış,

- Havayollarının uçuş bilgilerine kolay erişim,

- Uçuş kurallarını anında görebilme,

- Son an iptallerinin ya da değişikliklerinin anında yapılabilmesi,

- En düşük fiyatı takip edip uygulayabilme olanağı,

- Oto kiralama olanağı sağlama,

- Sisteme dâhil konaklama işletmelerinin rezervasyonlarını yapabilme olarak sayabiliriz.

Küresel dağıtım sistemlerinden sonra 1990 'l1 yıllarda gelişen internet teknolojisi seyahat işletmelerine ayrı bir ivme kazandırmıştır. Bu yolla işletmeler turistik ürünlerinin tanıtım ve satışlarını internet üzerinden yapmaya başlamışlardır. İnternetin hızlı gelişimi dağıtım kanallarının maliyetlerini düşürmüştür. İnternet kullanımının yaygınlaşması seyahat acentalarının geleceğine yönelik tartışmaları da beraberinde getirmiştir. Reinders ve Baker 1997 yılında yaptıkları çalışmalarında seyahat acentalarının \%20'sinin kapanacağını ya da büyük seyahat acentaları ile birleşeceğini belirtmişlerdir. $\mathrm{O}$ yıllardan günümüze seyahat endüstrisinde uluslararasılaşma gerçekten de hızla artmış bugün de satın alma işbirliklerinin hızla devam ettiği görülmektedir. Fakat seyahat acentalarının tamamen ortadan kalkmasının söz konusu olmayacağını savunanlar da bulunmaktadır. O'Connor (1999) seyahat acentalarının tüketicilere sağladığı bilgi, sundukları deneyim nedeni ile büyüme ve gelişimin devam edeceğini belirtmiştir. Birçok araştırmacı internetin seyahat acentalarının rolünü değiştireceğini savunmuşlardır.

Bugün değişen rollerin arkasında yine küresel dağıtım şirketlerini görmek mümkündür. Özelliğini yitireceği düşünülen küresel dağıtım şirketleri bugün sadece seyahat işletmelerine yukarıda tanımladığımızhizmet olanaklarını sunmamakta, aynı zamanda pek çok havayolunun, seyahat işletmesinin ve internet üzerinden satış yapan (bilet, oda) firmaların alt yapılarını desteklemektedir. Yine tur operatörlerine outgoing turlarında rezervasyon ve alt yapı sağlayıcılığı görevi üstlenmektedir.

Küresel dağıtım endüstrisinde, küresel pazarın hâkimi olan pek çok dağıtım sistemleri arasında ciddi bir rekabet vardır. AMADEUS, GALİLEO, SABRE ve WORLDSPAN bu pazarın hâkimi olan en önemli dört sistemdir.Şekil 2'de bu 4 küresel dağıtım sisteminin kuruluş yapıları görülmektedir. Bu çalışmada AMADEUS incelenecektir. 


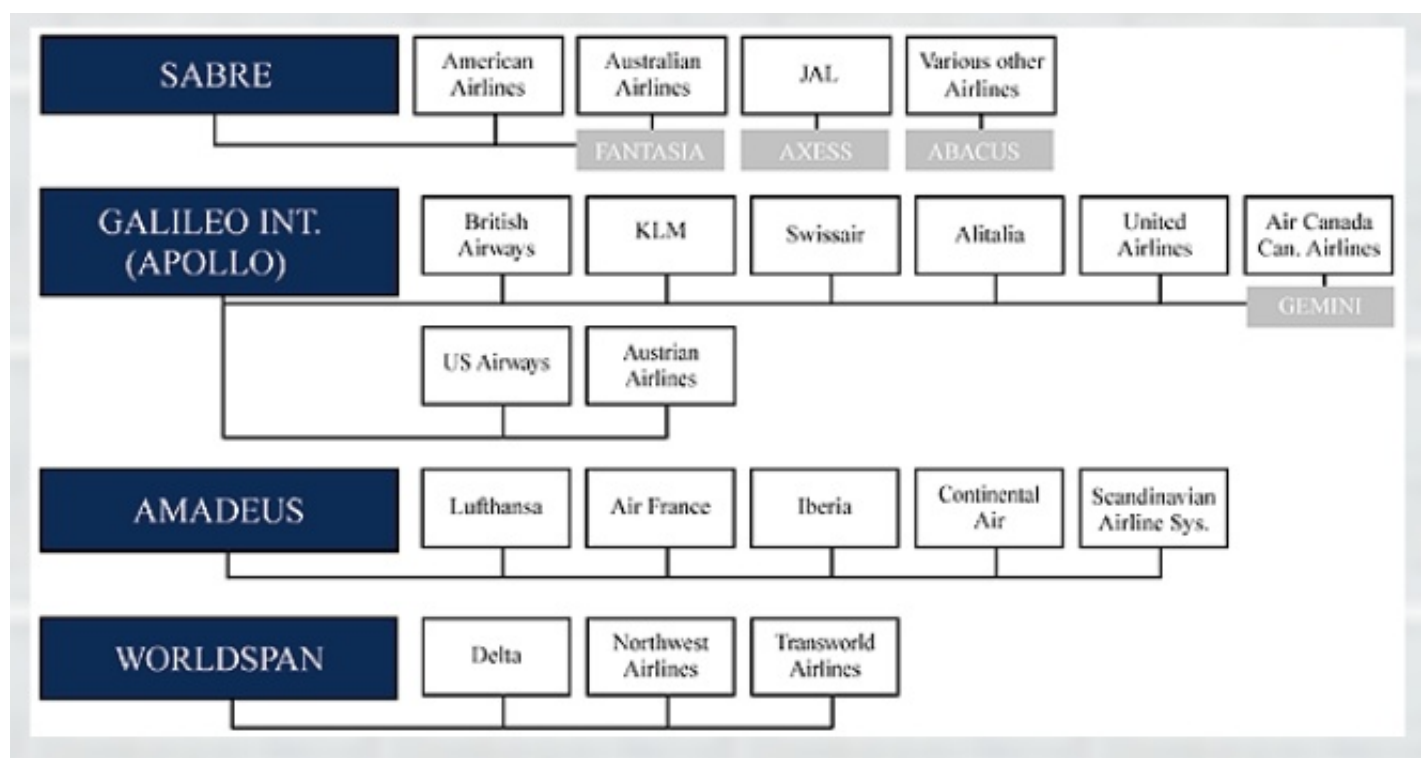

Şekil 2. KüreselDağıtım Sistemlerinin

\section{Gds'lere Bir Örnek: AMADEUS}

AMADEUS, turizm sektöründe, rezervasyon ve bilgi ihtiyacını karşılamak üzere Elektronik Rezervasyon Dağıtım Sistemi olarak 1987 yılında Air France, Iberia, Lufthansa ve SAS ortaklığı ile kurulmuştur.

Seyahat sağlayıcıları ve seyahat acenteleri için araştırma, fiyatlandırma, rezervasyon ve bilet satış hizmetlerinin yanı sıra gerçek zamanlı hareket hizmeti sağlayan AMADEUS grubunun dünya çapında 123 milliyetten 9.899 çalışanı bulunmaktadır.

AMADEUS küresel seyahat ve turizm sektörünün önde gelen bir işlemci ve ileri teknoloji çözüm tedarikçisi olarak seyahat sağlayıcılarına ve seyahat acentelerine son teknoloji çözümler sunmaktadır. AMADEUS Dağıtım iş kolu kanalı ile seyahat sağlayıcıları ve seyahat acentelerine sağlamış olduğu gerçek zamanlı arama, ücretlendirme, rezervasyon, biletleme ve diğer çözümleriyle ve bununla birlikte IT Çözümleri iş kolu kanalıyla seyahat sağlayıcılarına sunmuş olduğu (özellikle havayollarına) son derece geniş teknoloji çözümleri porföyü ile seyahat sağlayıcıların rezervasyon, envanter yönetimi ve kalkış kontrol yönetimi gibi belirli kritik iş süreçlerinin yönetilmesini sağlamaktadır.

AMADEUS'un Madrid'de merkez ofisi (Genel Merkez ve Pazarlama), Nice'de (Ürün Geliştirme) ve Erding'te (Operasyonlar - Veri İşleme Merkezi) ve Miami, Buenos Aires, Bankok ve Dubai'de bölgesel ofisleri bulunmaktadır. Pazar düzeyinde, AMADEUS, 195 ülkeyi kapsayan 73 yerel AMADEUS Ticari Kuruluşu aracılığılyla müşteri faaliyetlerini yürütmektedir. 
Müşteri grupları arasında havayolları (geleneksel, yerel, düşük maliyetli ve charter havayolları), oteller (zincir ve bağımsız oteller), tur operatörleri, sigorta şirketleri, kara ve deniz taşıma şirketleri (araba kiralama şirketleri, demiryolu şirketleri, feribot ve gemi seferleri) olmak üzere seyahat sağlayıcılar, seyahat satıcıları olarak seyahat acenteleri (geleneksel ve online) ve seyahat satın alanlar(kurumlar ve seyahat edenler) bulunmaktadır.

AMADEUS'unhizmet üreticileri; 763Uçuş tarifesi bulunan havayolu, 487rezervasyon yapılabilen havayolu, 153 AMADEUS "Sistem Kullanıcısı" olan havayolu, 27 araç kiralama şirketi, 73,916 otel ve 18 tane de Kruvaziyer şirketinden oluşmaktadır.

Toplam 88,878 seyahat acentası, 28,128 havayolu satış ofisi ve 36,000 araba kiralama şirketinde AMADEUS kullanılmaktadır.

AMADEUS'un dünya genelinde 16 AR\&GE (Araştırma ve Geliştirme) Merkezi mevcuttur. Nice, Londra, Sidney, Antwerp, Aachen, Frankfurt, Boston, Miami, Toronto, Strasburg, Tucson, Bangalor, Bogota, Varşova, Istanbul ve Bangkok'taki AR\&GE merkezlerinde, toplamda 4500'den fazla AMADEUS çalışanı hizmet vermektedir (www.amadeus.com).

Ülkemizde de 1992 yılından bu yana on-line çalışmaya başlamış ve 1993 yılında Türkiye'de ilk Amadeus terminalleri bağlanmıştır. Sadece seyahat işletmeleri değil günümüzde neredeyse turizm ve seyahat eğitimi veren üniversite düzeyindeki okulların çoğunda ders olarak okutulmakta ve öğrencilere sertifika vermektedir.

\section{AMADEUS İle Gerçekleștirilen İșlemler ve Seyahat İşletmeleri Üzerindeki Etkileri}

Seyahat işletmeleri AMADEUS ile ulaşım ve konaklama rezervasyonları yapabilmektedirler. Bugün pek çok havayolu biletlerinin yanında tren biletleri dâhi bu sistem ile kesilebilmektedir. Sadece tüm dünyada küresel firmalarla değil yerel bazda da işletmelere destek hizmetler sunmaktadır. Örneğin ülkemizde yerel olarak Atlas Jet ve Varan Turizmbu sistem içinde bulunmaktadır.

Küresel dağıtım sistemleri, kullanan seyahat acentelerine, bağlı olan işletmelere ve müşterilere çeşitli avantajlar getirmektedir. Ancak bunun yanı sıra seyahat acentelerine getirdiği bazı dezavantajlar da söz konusudur.

Seyahat acenteleri, AMADEUS sayesinde müşterilerine daha hızlı ve kaliteli hizmet sunma imkânına sahip olabilmektedir. Ulaşılan bilgilerin kesinliği ve kapsamının çok geniş olması seyahat acentelerinin sunabileceği alternatifleri arttırmaktadır. Klasik yöntemler ile yapılan rezervasyonlarda, seyahat acenteleri çok sayıda telefon görüşmesi yapmak ve daha fazla personel çalıştırmak durumundadır. Ancak AMADEUS kullanılarak daha az zamanda kesin bilgilere ulaşılarak rezervasyonlar gerçekleştirilebilmektedir. Finansal maliyetlerin dışında klasik yöntemler zaman kaybına da neden olmaktadır. Tüm bu maliyetlerden AMADEUS sayesinde kurtulmak mümkündür. 
AMADEUS'un uluslararası alanda hizmet veren acenteler için işlemleri kolaylaştırarak dünyayı küçülttüğünü söylemek mümkündür. Oluşturduğu iletişim ağı ile sürekli ve kesin bilgi elde etmek mümkündür. Turistik ürünü oluşturan unsurların bir arada sunulması ve müşteriler için zaman kaybını azaltması, farklı seçenekleri karşılaştırma olanağı sağlaması; seyahat acentelerinin satış ve pazarlama faaliyetlerini kolaylaştırmakta ve etkinleştirmektedir. Bu nedenle acentelerin satışları artmakta, komisyonlardan elde ettikleri gelir yükselmekte ve pazar payı büyümektedir.

Bağlı işletmelere uluslararası düzeyde tanıtım, satış yapma ve çok sayıda tüketiciye ulaşma olanağı sağlayan AMADEUS, aynı zamanda farklı ülkelerdeki işletmeler arasında hızlı ve kesin bir iletişim imkânı sunmaktadır. Ayrıca bu işletmelerin yabancı işletmeler ile rekabet etmesine de olanak tanımaktadır. Bağlı işletmelerin kendilerine gelen rezervasyon taleplerini kontrol etme, onaylama ve seyahat acentesine bilgi verme gibi işlemleri zaman harcamadan sistem üzerinde anında gerçekleştirmeleri de AMADEUS aracılığ 1 ile mümkün olmaktadır. Rezervasyonların merkezileşmesi, işletme içi denetimi de kolaylaştırmaktadır.

Müşteriler için ise AMADEUS'un en büyük avantajı, çok sayıda seçenek sunması ve karşılaştırma yapmaya olanak tanımasıdır. Seyahat ile ilgili tüm talepleri karşılaması, müşterilerin seyahat organizasyonu için vakit harcamalarını önlemekte ve garantili rezervasyonlar ile sorun yaşamalarını engellemektedir. Ayrıca Internet üzerinden rezervasyon yapma olanağı, müşterilere herhangi bir aracıya ihtiyaç olmaksızın bireysel olarak seyahat planlarını hazırlama ve özgürce seçim yapma şansı da tanımaktadır.

AMADEUS'un sürekli gelişen turizm endüstrisinde seyahat acentelerine sağladığ1 avantajlarının yanı sıra bir takım dezavantajları da söz konusudur. Sistemin kuruluş maliyetinin çok yüksek olması, küçük acentelerin bu olanaklardan yoksun kalmasına ve rekabet avantajını yitirmesine neden olmaktadır. Acentedeki AMADEUS terminal sayısını arttırmak ve taahhüt edilen satış rakamına ulaşamamak ek maliyetler getirmektedir. Ayrıca bu sistemi kullanabilmesi için personelin iyi bir eğitimden geçmesi gerekmektedir. Bu eğitimler acentelerin zaman kaybı ve maliyet yükünü de beraberinde getirmektedir.

Dünyanın en büyük küresel dağıtım sistemlerinden birisi olan AMADEUS, teknolojinin güncelleştirilmesini, satışları arttırmak için faaliyetlerin daha etkin hale getirilmesini sağlamaktır.

AMADEUS internet teknolojisinin gelişimi ile yeni sistemler geliştirerek kendi sistemine dâhil olan firmalara da kolaylıklar sunmaktadır.

\section{SONUÇ}

Günümüzde olağanüstü bir hızla ucuzlayarak yaygınlık kazanan bilgi teknolojileri, uluslararası alandaki değişim sürecinde, küreselleşmeyi hızlandırmaktadır. Bilgi ve iletişim teknolojileri sayesinde bilgisayarlar, dijital donanımlar, faks makineleri, cep telefonları, uydu yayınları gibi yeni ürün ve hizmetlerin ortaya çıkışı toplam üretimi artırmakta ve yeni iş olanakları yaratmaktadır. İnternet yoluyla yapılan ticaret (e-ticaret), dijital reklam, sınır-ötesi 
üretim, yeni pazarlama teknikleri, yeni organizasyon ve yönetim teknikleri ile ekonomik etkinlik artmaktadır.

Gelişmekte olan ülkelerin kalkınmasında turizmin önemi sürekli vurgulanmaktadır. Turizm de yeni ekonomik sürecin bir parçasıdır. Bu süreç içinde turizm de yaşanan gelişmelerden etkilenmektedir.

Dünya seyahat ve turizm endüstrisi, büyük değişimlerle karşılaşmaktadır ve bu alanda faaliyet gösteren şirketler için rekabet güçlerini korumanın tek yolu çevrelerindeki değişim ve eğilimleri yakından izlemektir. Aynı şekilde, rekabetçi dünya turizmi ortamında turizm pastasından büyük pay almak isteyen ülkelerin de yeni ekonominin getirdiği değişimleri yakından izleyerek turizm politikalarını o yönde oluşturmaları gerekmektedir.

Turizm işletmelerinin gelişen bilgi teknolojilerinden faydalanmasına verilecek örneklerden biri de küresel dağıtım sistemleridir. Küresel dağıtım sistemleri, sürekli değişen ve gelişen turizm endüstrisi koşullarında oluşturulmuş ve endüstriye gerekli tüm bilgileri sağlamak için çalışan sistemlerdir. Bu sistemlerin ortak özelliği turistik ürünün bileşenlerini rezervasyonu yapacak olan seyahat acenteleri ya da bireyler için bir araya getirmesidir. Başlangıçta yalnızca seyahat acentelerinin kullandığı sistemler olarak ortaya çıkmasına rağmen bugün Internet'in yaygınlık ve işlerlik kazanması ile müşterilerin de bireysel olarak kullanabildiği bir sistem halini almıştır.

AMADEUS, küresel dağıtım sistemlerinin en büyük ve en önemlilerinden birisidir. AMADEUS'un sağladığı teknik destek ile acentelerin endüstriye ve sisteme ilişkin sorunları profesyonelce ele alınarak çözüme kavuşturulmaktadır. Internet üzerinden bireysel müşterilere de ulaşabilen AMADEUS, ulaşım, konaklama, araba kiralama ve pek çok farklı hizmet sunan işletmeleri bir araya getirerek müşterilerin çeşitli alternatifler arasından kendilerine en uygun seçeneği bulmasına yardımcı olmaktadır.

Küresel dağıtım sistemleri, 1990'lı y1llardan itibaren sürekli bir gelişme ve yeni teknolojiye ayak uydurma eğilimi göstermektedir. İşletmelere getirdiği ek maliyetlerin yanında sağladığı faydalar düşünüldüğünde, seyahat endüstrisinde faaliyetlerin geleneksel yöntemlere göre kolaylaştığı söylenebilir. Teknoloji ve seyahat endüstrisi gelişmeye devam ettikçe küresel dağıtım sistemleri ve dolayısı ile AMADEUSda gelişmeye devam edecek ve günün koşullarına göre şekil alacaktır. Teknolojinin ilerlemesi ve ihtiyaçların çeşitlenmesi bu sistemleri gelişmeye zorlamaktadır.

\section{KAYNAKÇA}

Adams, B., (2002). Tech Talk, Hotel \& Motel Management, Vol.217, No.14, (134-144).

Aktan C.C.\&Tunç, M. (1998).Bilgi Toplumu ve Türkiye, Yeni Türkiye Dergisi, Ocak-Şubat, 118-134.

Buhalis, D. (1998). Strategic Use of Information in theTourismIndustry, Tourism Management, Vol.19, No.5, 409-421. 
Buhalis, D. \& Main, H. (1998). Information Technology in Peripheral Small andMediumHospitality Enterprises: Strategic Analysis and Critical Factors,International Journal of ContemporaryHospitality Management, Vol.10, No.5, 198-202.

Cooper, C., John Fletcher, David Gilbrth\&StephenHill. (1998). Tourism: PrinciplesandPractises, (Ed. RebeccaShepherd) Essex: Longman.

Coşkun, İ.O. \& Yüksek, G. (2010). Turizm İşletmelerinde Bilgi Teknolojileri TÜROFED, Say1 51.

Erdoğan, M. \& Erdoğan, N. (1996). Muhasebede Bilgisayar Kullanımı,Eskişehir.

Kurgun, A. \& Kurgun, H. \&Güripek, E. (2007). Turizm Pazarlamasında Küresel Dağıtım Sisteminin (Global Distribution System- GDS) Stratejik Rolü, Dokuz Eylül Üniversitesi Sosyal Bilimler Enstitüsü Dergisi, Cilt 9, Say1: 1, 262-274. 07.01.2013 tarihinde http://www.sbe.deu.edu.tr/dergi/cilt9.say\%C4\%B11/9.1\%20kurgun\%20kurgun\%20g\%C3\%BCri pek.pdf adresinden erişildi.

O'Connor, P. (1999). Electronics Information Distribution in TourismandHospitality. CAB International, Oxford, UK.

Reinders, J. ve Baker, M. (1997). TheFuturefor Direct Retailing of Travel andTourismProducts: TheInfluence of Information Technology, Proceedings of The International Conference on Information andCommunication Technologies in Tourism, Edinburgh, Scotland, 119-127.

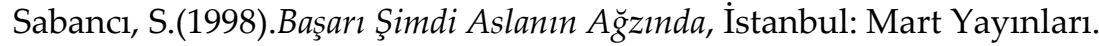

Yarcan, Y. (1998). Türkiye'de Turizm ve Uluslararasılaşma, İstanbul: Boğaziçi Üniversitesi Matbaası.

Yılmaz, B. S. \& Yılmaz, Ö.D. (2004). Küreselleşme ve Bilgi Teknolojilerinin Turizm Endüstrisine Etkileri, 1. Balıkesir Ulusal Turizm Kongresi, 15-16 Nisan, Balıkesir.03.01.2013 tarihinde http://tre.docdat.com/tw_files2/urls_53/7/d-6624/7z-docs/6.pdf adresinden erişildi.

Yolal, M. (2003).Türkiye'deki Küçük ve Orta Büyüklükteki Konaklama Işletmelerinde Bilgi Teknolojileri Kullanımı, Eskişehir: Anadolu Üniversitesi Yayınları.

Mutch, A. (1995). IT and Small Tourism Enterprises: A Case Study of Cottage-LettingAgencies,Tourism Management, Vol.16, No.7, 533-539.

Zhou, Z. (2003). E-Commerce and Information Technology in HospitalityandTourism, California: ThomsonDelmar Learning.

WwW.amadeus.com10.01.2013 tarihinde erişildi. 